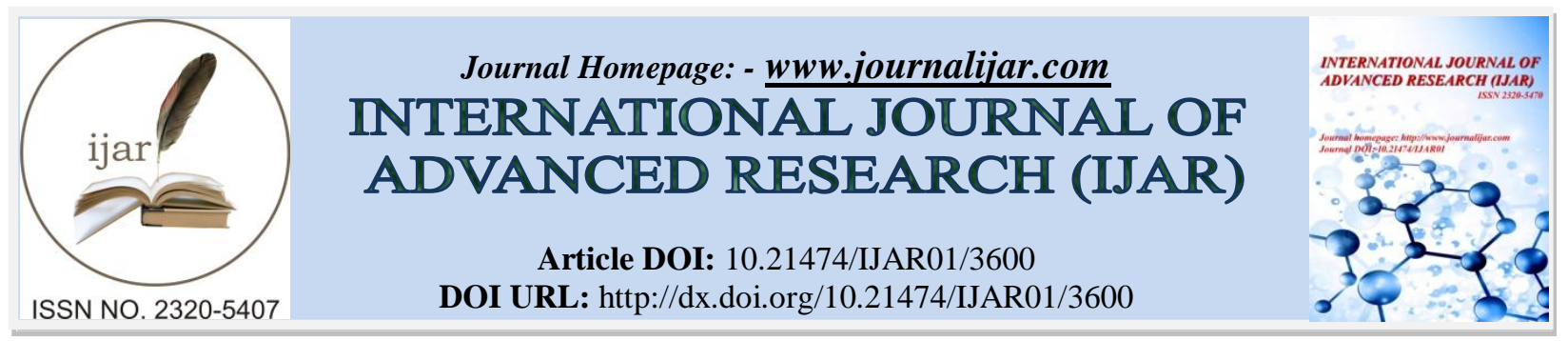

RESEARCH ARTICLE

\title{
SYNTHESIS AND CHARACTERIZATION OF 16, 17-MEMBERED TETRA AZA MACROCYCLIC COMPLEXES.
}

\author{
Avinash Kumar, Neeraj Kumar, Kuldeep Singh and Kushmander Singh. \\ S.S.M.V. (P.G.) College, Shikarpur Bulandshahr, India.
}

\section{Manuscript Info}

Manuscript History

Received: 06 January 2017

Final Accepted: 02 February 2017

Published: March 2017

\begin{abstract}
Oxo tetra aza macrocylic transition metal complexes $\left[\mathrm{M}\left(\mathrm{C}_{15} \mathrm{H}_{25} \mathrm{~N}_{5} \mathrm{O}\right) \mathrm{Cl}_{2}\right]$ or $\left[\mathrm{M}\left(\mathrm{C}_{16} \mathrm{H}_{27} \mathrm{~N}_{5} \mathrm{O}\right) \mathrm{Cl}_{2}\right] ; \mathrm{M}=\mathrm{Co}(\mathrm{II}), \mathrm{Ni}(\mathrm{II}), \mathrm{Cu}(\mathrm{II})$ and $\mathrm{Zn}(\mathrm{II})$ have been synthesized by the template condensation reaction of $\mathrm{O}$-amino benzoic acid, triethylene tetramine, and 1,3-dibromo propane or dibromo methane in methanol medium. All the complexes have been characterized on the basis of elemental analysis, IR, NMR, EPR, UV-vis, conductivity and magnetic moment data. All the complexes are non ionic in nature and exhibit an octahedral geometry.
\end{abstract}

Copy Right, IJAR, 2017,. All rights reserved.

\section{Introduction:-}

The pioneering work on metal template synthesis by Curtis ${ }^{(1)}$ and Busch ${ }^{(2)}$ exposed the field of macrocyclic chemistry as the major area of research interest. Polyamide macrocycles are of particular interest in view of their two possible donor sites, nitrogen and oxygen atoms. Further more, many of polyamide macrocyclic complexes function like porphyrins in catalyzing organic oxidation reactions ${ }^{(3-8)}$. Amide macrocycles bear the dual structural features of macrocyclic tetra amines and oligopeptides and can stabilize higher oxidation states of some of the metal ions ${ }^{(9,10)}$. Some of these compounds have been used as metal ion carriers ${ }^{(11,12)}$. Transition metal(II) complexes of amide macrocycles have interesting properties and can be considered as models for metalloproteins and oxygen carriers ${ }^{(13,14)}$. The present work describes the synthesis and characterization of a new series of oxotetraamine macrocyclic complexes obtained by the template reaction of o-aminobenzoic acid, triethylene tetramine and dibromo propane.

\section{Material and methods}

o-Amino benzoicacid, 1,3-diamino propane, diamino ethane and triethylene- tetra amine (all E. Merck were used as purchased. The metal salts were AR grade reagents obtained from BDH.

Preparation of dichloro (3-oxo-1,2-benzo-4,7,10,13-16 penta aza cyclo-hexadecane) $\mathrm{metal}_{(\mathrm{II})}\left[\mathrm{ML}^{1} \mathrm{Cl}_{2}\right][\mathrm{M}$ $\mathrm{Co}^{\mathrm{II}}, \mathrm{Ni}^{\mathrm{II}}, \mathrm{Cu}^{\mathrm{II}}$ and $\mathrm{Zn}^{\mathrm{II}}$ ]

To a methanolic solution of metal salt $(0.01 \mathrm{~mol})$ were added simultaneously triethylenetetra amine $(0.01 \mathrm{~mol})$ and o-aminobenzoic acid $(0.01 \mathrm{~mol})$ through the each neck of a two-necked round bottom flask. The resultant mixture was stirred for about $7 \mathrm{hrs}$ and then dibromo ethane was added. The stirring was continued for another $3 \mathrm{hrs}$ which resulted in the formation of the title compounds. The title compounds were isolated by filtration, washed several times with methanol and then with $\mathrm{Et}_{2} \mathrm{O}$ and dried in vacuole. The purity of the final products was confirmed by TLC as follows: The complexes were dissolved in DMF using EtOAc $(80 \%) \mathrm{MeOH}(15 \%)$ and $\mathrm{MeCO}_{2} \mathrm{H}$ as eluent. A single spot was seen in each case on developing in an iodine chamber.

Preparation of dichloro (3-oxo-1,2-benzo-4,7,10,13,17 pentaazacylohepta) decane metal(II), $\left[\mathrm{ML}^{2} \mathrm{Cl}_{2}\right]\left[\mathrm{M}^{2}=\right.$ $\mathrm{Co}^{\mathrm{II}}, \mathrm{Ni}^{\mathrm{II}}, \mathrm{Cu}^{\mathrm{II}}$ and $\mathrm{Zn}^{\mathrm{II}}$ )

The procedure used for these compounds was similar to the above method except that 1,3-dibromo propane was added instead of dibromo ethane in the final step. ${ }^{(15,16)}$ 


\section{Results and Discussion:-}

The template condensation reaction of triethylene tetraamine, o-aminobenzoic acid and dibromo alkane resulted in the formation of macrocyclic complexes as shown in Scheme I. All these compounds were obtained as polycrystalline solids. They are freely soluble in dimethyl sulphoxide, dimethylformamide and acetonitrile. The results of elemental analysis are consistent with their proposed 1:1 (metal to ligand) stoichiometry. All the complexes exhibited low molar conductivity values in DMSO (13-20 $\mathrm{ohm}^{-1} \mathrm{~cm}^{2} \mathrm{~mol}^{-1}$ ) which support ${ }^{(17)}$ the non-ionic nature of these compounds.

\section{IR-Studies:-}

The IR spectra of all the complexes exhibited a single sharp band in the region $3250-3270 \mathrm{~cm}^{-1}$ which may be assigned to coordinated NH stretching vibration. This information together with the appearance of four bands in the ranges 1680-1710, 1530-1570, 1250-1260 and 650-670.

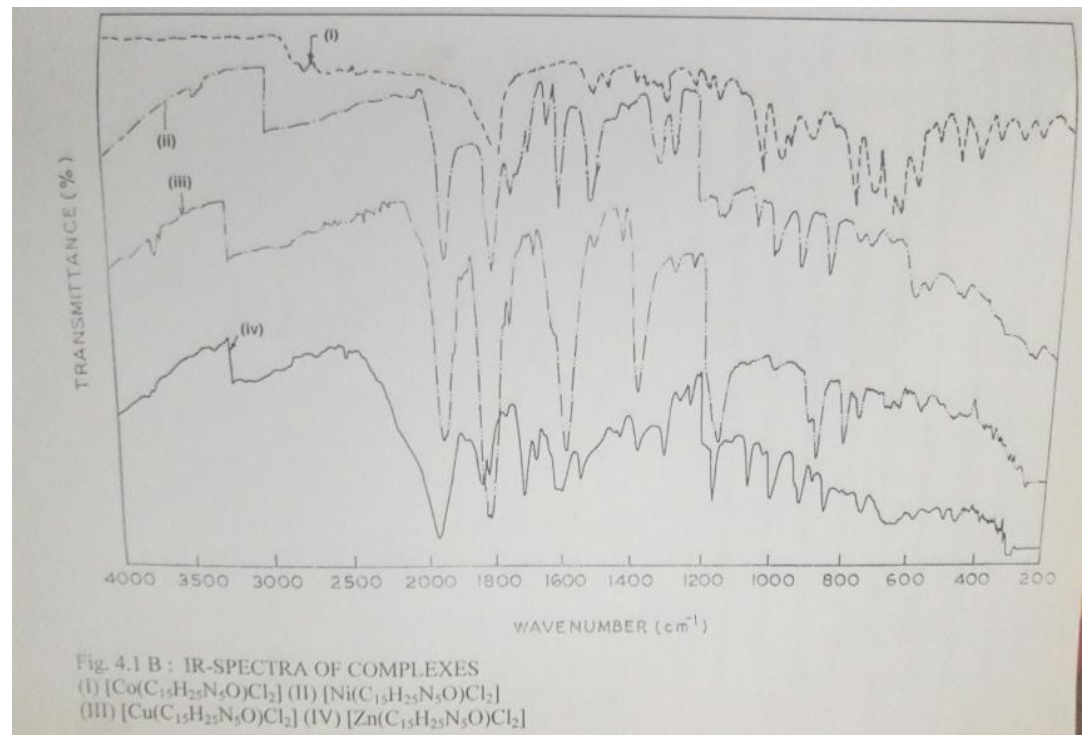

$\mathrm{cm}^{-1}$ assignable ${ }^{(18)}$ to amide $\mathrm{I}(\mathrm{vC}=\mathrm{O})$; amide $\mathrm{II}(\mathrm{vC}-\mathrm{N}+\delta \mathrm{NH})$, amide III $(\delta \mathrm{NH})$ and amide IV $(\phi \mathrm{C}=\mathrm{O})$ bands respectively, suggests the formation of the proposed macrocyclic framework. The absorption bands appearing in the region 2880-2930 and 1410-1460 $\mathrm{cm}^{-1}$ in all the ligands may reasonably be assigned to the $\mathrm{CH}$ stretching and $\mathrm{CH}$ bending vibrational modes, respectively. The appearance of a low medium intensity band in the region $410-450 \mathrm{~cm}^{-1}$ assignable to $v(\mathrm{M}-\mathrm{N})$ further confirms the involvement of nitrogen in coordination. However, no complex gave bands assignable to primary amines or carboxylic acid groups.

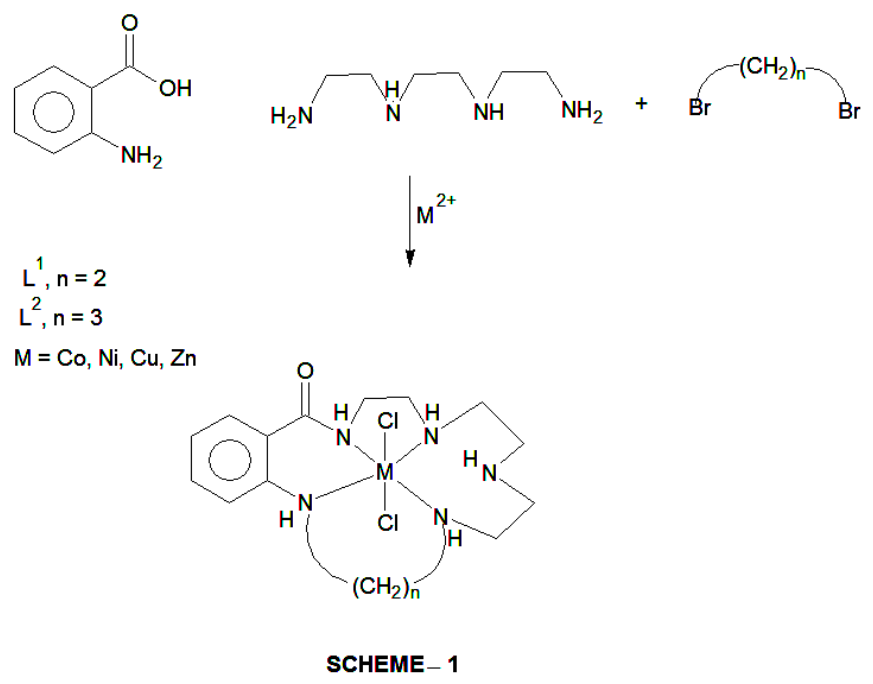




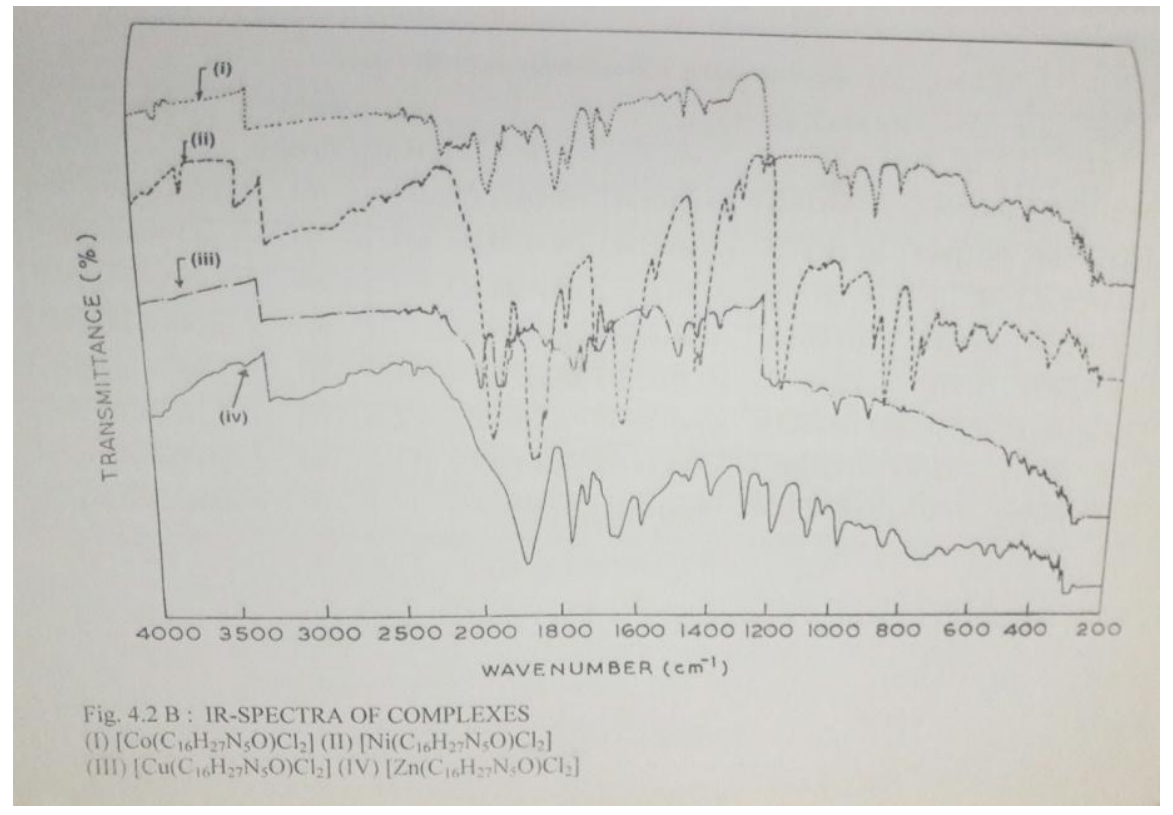

Table 1:- Characterization data of the compounds.

\begin{tabular}{|c|c|c|c|c|c|c|c|c|}
\hline \multirow{2}{*}{$\begin{array}{l}\text { S. } \\
\text { No. }\end{array}$} & \multirow[t]{2}{*}{ Compound } & \multirow{2}{*}{$\begin{array}{c}\text { Melting } \\
\text { point }\left({ }^{\circ} \mathbf{C}\right)\end{array}$} & \multirow{2}{*}{$\begin{array}{l}\mu \text { eff. } \\
\text { (B.M.) }\end{array}$} & \multicolumn{5}{|c|}{ Found (Calcd.), \% } \\
\hline & & & & M & $\mathbf{C l}$ & $\mathrm{C}$ & $\mathbf{H}$ & $\mathbf{N}$ \\
\hline 1. & {$\left[\mathrm{Co}\left(\mathrm{C}_{15} \mathrm{H}_{25} \mathrm{~N}_{5} \mathrm{O}\right) \mathrm{Cl}_{2}\right]$} & 140 & 4.03 & $13.82(13.99)$ & $16.70(16.86)$ & $42.61(42.76)$ & $5.80(5.93)$ & $16.50(16.64)$ \\
\hline 2. & {$\left[\mathrm{Ni}\left(\mathrm{C}_{15} \mathrm{H}_{25} \mathrm{~N}_{5} \mathrm{O}\right) \mathrm{Cl}_{2}\right]$} & 145 & 3.10 & $13.80(13.95)$ & $16.70(16.87)$ & $42.70(42.78)$ & $5.80(5.94)$ & $16.50(16.63)$ \\
\hline 3. & {$\left[\mathrm{Cu}\left(\mathrm{C}_{15} \mathrm{H}_{25} \mathrm{~N}_{5} \mathrm{O}\right) \mathrm{Cl}_{2}\right]$} & 163 & 1.72 & $14.80(14.93)$ & $16.53(16.68)$ & $42.20(42.29)$ & $5.73(5.87)$ & $16.32(16.44)$ \\
\hline 4. & {$\left[\mathrm{Zn}\left(\mathrm{C}_{15} \mathrm{H}_{25} \mathrm{~N}_{5} \mathrm{O}\right) \mathrm{Cl}_{2}\right]$} & 170 & - & $15.19(15.29)$ & $16.50(16.61)$ & $42.0(42.11)$ & $5.70(5.84)$ & $16.27(16.37)$ \\
\hline 5. & {$\left[\mathrm{Co}\left(\mathrm{C}_{16} \mathrm{H}_{27} \mathrm{~N}_{5} \mathrm{O}\right) \mathrm{Cl}_{2}\right]$} & 145 & 4.09 & $13.40(13.55)$ & $16.12(16.32)$ & $44.0(44.14)$ & $6.10(6.20)$ & $15.90(16.09)$ \\
\hline 6. & {$\left[\mathrm{Ni}\left(\mathrm{C}_{16} \mathrm{H}_{27} \mathrm{~N}_{5} \mathrm{O}\right) \mathrm{Cl}_{2}\right]$} & 154 & 3.10 & $13.39(13.50)$ & $16.20(16.33)$ & $44.0(44.14)$ & $6.10(6.21)$ & $15.92(16.10)$ \\
\hline 7. & {$\left[\mathrm{Cu}\left(\mathrm{C}_{16} \mathrm{H}_{27} \mathrm{~N}_{5} \mathrm{O}\right) \mathrm{Cl}_{2}\right]$} & 162 & 1.73 & $14.30(14.45)$ & $16.0(16.15)$ & $43.60(43.68)$ & $6.0(6.14)$ & $15.78(15.92)$ \\
\hline 8. & {$\left[\mathrm{Zn}\left(\mathrm{C}_{16} \mathrm{H}_{27} \mathrm{~N}_{5} \mathrm{O}\right) \mathrm{Cl}_{2}\right]$} & 173 & - & $14.70(14.81)$ & $15.89(16.08)$ & $43.40(43.50)$ & $6.0(6.11)$ & $15.69(15.85)$ \\
\hline
\end{tabular}

\section{NMR-Studies:-}

The ${ }^{1} \mathrm{H}$ NMR spectra of zinc macrocyclic complexes showed a multiplet, in the region 8.41-8.56 ppm which can be assigned $^{(19)}$ to amide (NH-CO) protons. This clearly shows that the condensation of o-aminobenzoic acid and triethylene tetraamine, has indeed taken place. A multiplet appearing in the region 3.35-3.61 ppm may be ascribed to the methylene protons $\left(\mathrm{CO}-\mathrm{N}-\mathrm{CH}_{2}\right)$. The complexes showed a multiplet in the region 6.98-7.26 ppm corresponding to the phenyl ring protons. Another multiplet observed for all the complexes in the region 2.58-2.60 ppm may be assigned to the methylene proton between the nitrogen atoms $\left(-\mathrm{CH}_{2}-\mathrm{N}\right)$. The spectra of all the complexes showed multiplet in the region $6.21-6.40 \mathrm{ppm}$ which corresponds ${ }^{(20)}$ to the secondary amino protons $(\mathrm{C}-\mathrm{NH})$. No compound exhibited signal corresponding to the carboxylic or secondary amino protons, which supports the proposed structure shown in Scheme 1.

\section{EPR-Studies:-}

The EPR spectra of polycrystalline copper(II) macrocyclic complexes at room temperature show a single band with $\mathrm{g}_{\|}$and $\mathrm{g}_{\perp}$ values 2.24, 2.30 and 2.13, 2.09 respectively. None of the complexes exhibited hyperfine splitting which may be due to the fact that the paramagnetic centres are not diluted. The existence of $g_{\|}>g_{\perp}$ values $2.24,2.30$ and 2.13, 2.09 respectively. None of the complex exhibited hyperfine splitting which may be due to the fact that the paramagnetic centres are not diluted. The existence of $g_{\|}>g_{\perp}$ suggests ${ }^{(21)}$ that $d x^{2}-y^{2}$ is the ground state. The $g$ values are related to the axial symmetry parameters, $G$ by the following expression, $G=\left(g_{\|}-2\right) /\left(g_{\perp}-2\right)$. The $G$ values measure the extent of exchange interaction between copper centres in the polycrystalline solid. If $G>4$, exchange interaction is negligible, and if $G<4$, considerable exchange interaction exists in the solid complexes ${ }^{(22)}$. In the present case, $\mathrm{G}$ values were found to be 1.85 and 3.33 . 


\section{Electronic Spectral Studies:-}

The electronic spectra of cobalt complexes exhibited two ligand field bands in the ranges 13800-14000 and 22200-22300 $\mathrm{cm}^{-1}$ which are assignable ${ }^{(23,24)}$ to ${ }^{4} \mathrm{~T}_{1 \mathrm{~g}}(\mathrm{~F}) \rightarrow{ }^{4} \mathrm{~A}_{2 \mathrm{~g}}(\mathrm{~F})$ and ${ }^{4} \mathrm{~T}_{1 \mathrm{~g}}(\mathrm{~F}) \rightarrow{ }^{4} \mathrm{~T}_{1 \mathrm{~g}}(\mathrm{P})$ transitions respectively in an octahedral geometry ${ }^{(25)}$. The appearance of two bands in the electronic spectra of nickel complexes in the ranges $11550-11600$ and $17500-17650 \mathrm{~cm}^{-1}$ may be assigned ${ }^{(25)}$ to ${ }^{3} \mathrm{~A}_{2 \mathrm{~g}}(\mathrm{~F}) \rightarrow{ }^{3} \mathrm{~T}_{1 \mathrm{~g}}(\mathrm{~F})$ and ${ }^{3} \mathrm{~A}_{2 \mathrm{~g}}(\mathrm{~F}) \rightarrow{ }^{3} \mathrm{~T}_{1 \mathrm{~g}}(\mathrm{P})$ transitions, respectively suggesting an octahedral geometry for $\mathrm{Ni}^{2+}$ complexes. The electronic spectra of copper complexes exhibited two well-discernible bands in the ranges 16400-16700 and 18800-19100 $\mathrm{cm}^{-1}$ assignable ${ }^{(26-28)}$ to ${ }^{2} \mathrm{~B}_{1 \mathrm{~g}} \rightarrow{ }^{2} \mathrm{~B}_{2 \mathrm{~g}}$ and ${ }^{2} \mathrm{~B}_{1 \mathrm{~g}} \rightarrow{ }^{2} \mathrm{E}_{2 \mathrm{~g}}$ transitions, respectively which are characteristic of an octahedral geometry. The high intensity bands observed around $37000 \mathrm{~cm}^{-1}$ for all the complexes in the ultraviolet region of the spectra may be assigned as metal to ligand charge transfer transitions. The magnetic moment data (Table 1) for all the complexes are consistent with the high spin octahedral geometry around these metal ions which further supports the electronic spectral results. ${ }^{(29-31)}$

\section{References:-}

1. House, D.A. \& Chrtis, N.F., Chemy Ind. (London), (1961) 1708.

2. $\quad$ Blinn, E. \& Busch, D.H., Inorg. Chem. 7 (1986) 820.

3. Che, C.M. \& Cheng, W.K., J. Chem. Soc. Chem. Commun. (1986) 1443.

4. Drago, R.S., Cardon, B.B. \& Barnes, C.W., J. Am. Chem. Soc. 108 (1986) 2453.

5. Sanssine, L., Brazi, E., Robine, A., Mimoun, H., Fischev, J. \& Weiss R., J. Am. Chem. Soc. 107 (1986) 3534.

6. Shakir, M. \& Varkey, S.P., Polyhedron, 14 (1995) 1117.

7. Shakir, M., Varkey, S.P. \& Khan, T.A., Indian J. Chem., 34A (1995) 72.

8. Shakir, M. \& Varkey, S.P., Trans. Met. Chem., 19 (1994) 606.

9. Lampeka, Y.D. \& Lampeka, S.P., J. Coord. Chem. 21 (1983) 451.

10. Fabbrizzi, L., Perotti, A. \& Poggi, A., Inorg. Chem. 22 (1983) 1411.

11. Kimura, E., Dalimunte, S.A., Yamashita, A. \& Machica, R., J. Chem. Soc. Chem. Commun. (1985) 1041.

12. Kimura, E., Lin Y., Machida, R. \& Zenda, H., J. Chem. Soc. Chem. Commun, (1986) 1020.

13. Machida, R., Kimura, E. \& Kodama, M., Inorg. Chem. 22 (1983) 2055.

14. Hiroyashi, S., Tomosaku, I. \& Kazumasa, K., Jap. Pat, 62 (1987), 201, 361.

15. Reilley, C.N., Schmid, R.W. \& Sadak, F.A., J. Chem. Educ. 36 (1959) 619.

16. Vogel, A.I., Text book of quantitative inorganic analysis (Longmans, London), 1961.

17. Geary, W.J., Coord. Chem. Rev., 7 (1971) 81.

18. Arora, D.L., Lal K., Gupta, S.P. \& Sahni, S.K., Polyhedron, 5 (1986) 1499.

19. Parker D., Pulukkody K., Smith, F.C., Batsanov, A. \& Howard, J. A.K. J. Chem. Soc. Dalton Trans, (1996) 689.

20. Burgess, K., Lim, D., Kantto, K. \& Ke, C.Y., J. Org. Chem., 59 (1994) 2179.

21. Jain, M.C., Srivastava, A.K. \& Jain, P.C., Inorg. Chim Acta, 59 (1994) 2179.

22. Hathaway, B.J. \& Billing, D.E., Coord. Chem. Rev., 5 (1970) 143.

23. Lever, A.B.P., Inorganic Electronic Spectroscopy (Elservier, Amsterdam) 1984.

24. Rana, V.B., Singh, P., Singh, D.P. \& Teotia, Polyhedron, 1, (1982) 377.

25. Ragunathan, K.G. \& Bhardwaj, P.K., J. Chem. Soc. Dalton Trans, (1992) 2417.

26. Song, K.C., Choi, M.G., Ryu, D.H., Kim, K.N. \& Chang, S.K., Tetrahedron Lett. (2007) $48,5397$.

27. Valuer B. \& Leray, I., Inorg. Chim. Acta (2007) 360, 765.

28. Ikeda, A. \& Shinaki, S., Chem. Rev. (1997) 97, 1713.

29. Valuer, B. \& Leary, I., Coord. Chem. Rev; (2000) 205, 3.

30. Kim, J.s. \& Quang, D.T., Chem. Rev. (2007) 107, 3780.

31. Creavena, B.S., Donlona, D.F. \& McGinley, J., Coord. Chem. Rev. (2009) 253, 893. 